\title{
PORTO ALEGRE E A PRESENÇA DA CERÂMICA PORTUGUESA
}

\author{
Porto Alegre and the presence of the Portuguese potery
}

\section{Verônica Di Benedetti}

Arquiteta Urbanista. Graduada em Arquitetura e Urbanismo pela Universidade de Mogi das Cruzes. Especialista em restauro de materiais pétreos e cerâmicos pelo Instituto italiano Palazzo Spinell. Mestre em Geociências - UFRGS. veronicadibene@gmail.com

\section{Resumo}

Apesar das origens portuguesas da cidade de Porto Alegre, a existência das tão marcantes cerâmicas lusas, quase não são percebidas na cidade. Poucos registros ainda denotam sua presença. As fachadas azulejadas tão recorrentes nas cidades do sudeste e nordeste do país e até mesmo na cidade de Pelotas, interior do Estado do Rio Grande do Sul, aqui não figuram na paisagem urbana. Ao caminharmos pelas ruas do centro histórico ainda podemos perceber algumas poucas edificações que fazem do uso deste material, sua identidade visual. Buscando por registros desta herança portuguesa podemos ainda verificar que algumas edificações históricas mantém em seu interior alguns exemplares, como o Solar dos Câmara. Vasos e esculturas, de fabricação portuguesa da fábrica Santo Antônio do Vale da Piedade da cidade do Porto, hoje abrigadas em seu interior, já compuseram a leitura das fachadas marcando a transição do prédio do estilo colonial português ao eclético.

Palavras-chave: Faiança. Conservação. Arquitetura. Porto Alegre. Restauração

\section{Abstract}

In spite of the Portuguese origins of the city of Porto Alegre, the existence of the so remarkable Portuguese ceramics, are almost not perceived in the city. Few records still denote its presence. The tile facades so recurrent in the southeastern and northeastern cities of the country and even in the city of Pelotas, in the interior of the State of Rio Grande do Sul, do not appear here in the urban landscape. As we walk through the streets of the historic center we can still see a few buildings that make use of this material, its visual identity. Looking for records of this Portuguese heritage we can still verify that some historical buildings maintains in its interior some examples, such as Solar dos Câmara. Vases and sculptures, made in Portuguese from the Santo Antônio do Vale da Piedade factory in the city of Porto, now housed in the interior, have already made up the reading of the façades marking the transition from the Portuguese colonial style building to the eclectic one.

Keywords: Ceramics. Conservation. City. Porto Alegre. Restoration.

\section{Sumário}

1. Introdução; 2. Breve história da cerâmica; 3. Cerâmica portuguesa; 4. Porto Alegre e a cerâmica portuguesa; 5. Considerações finais; 6 . Notas; Referências 


\title{
1. INTRODUÇÃO
}

Porto Alegre, tem como data oficial de fundação 26 de março de 1772, quando foi elevada a condição de freguesia. Neste período Portugal já havia se firmado como uma referência na produção de cerâmicas, sendo respeitada e admirada em toda a Europa. Suas peças eram consideradas obras de grande valor estético ganhando status de obra de arte. A produção cerâmica portuguesa estava saindo da fase denominada "ciclo dos mestres", onde grandes pintores de telas e mural migraram para realizar obras consideradas de erudição, utilizando as cores branco e azul, tão característica das nossas construções encontradas no nordeste do país. Outras fases se seguiram a esta, mas Porto Alegre, não guarda reflexos de fácil percepção. Poucos são os representantes desta arte na cidade. Algumas poucas edificações revestidas externamente por azulejos e poucos ornatos de fachada podem ser conferidos, mas para isto é necessário ficar atento.

\section{BREVE HISTÓRIA DA CERÂMICA}

As manifestações culturais utilizam a cerâmica há vários séculos fazendo deste material a base para a representação tanto sacra quanto profana dos povos.

\begin{abstract}
A cerâmica constitui uma das principais manifestações de identidade cultural desde a origem das civilizações. Fruto do processo de transformação da argila, é um dos primeiros produtos de síntese da história da humanidade. (ALVA BALDERRAMA; VIDAL ALMAGRO; BESTUÉ CARDIEL, 2003)
\end{abstract}

A primeira peça cerâmica de que se tem registro é datada entre 25.000 e 23.000 anos a.C.. Trata-se da escultura intitulada Vênus de Dolni Vestonice, encontrada na República Tcheca.

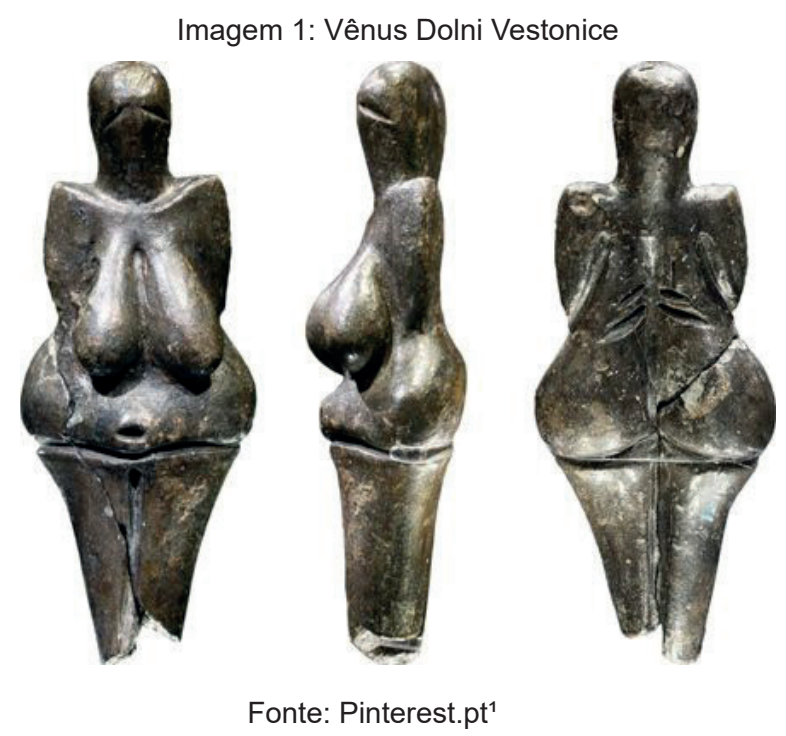

A ocorrência de achados arqueológicos de material cerâmico é bastante vasta e presente em todas as civilizações. Quem não conhece ou ouviu falar dos Guerreiros de Xi'an de 210 a.C. ou ainda dos vasos gregos e etruscos do período entre 1550 e 500 a.C.?

Os processos tecnológicos que fazem da cerâmica o que conhecemos hoje é resultado das interações entre os povos seja de forma pacífica ou não.

[...] a cerâmica se apresenta como resultado de complexos processos de migração cultural, re-elaboração, apropriação, transmigração e re-identificação do 
patrimônio arquitetônico e de seus elementos. E na base de tudo isto encontram-se a abertura de rotas comerciais, o descobrimento de novas regiões do mundo, e os fluxos migratórios que tais fluxos geraram. (ALVA BALDERRAMA; VIDAL ALMAGRO; BESTUÉ CARDIEL, 2003)

Os romanos por volta do século I d.C., dominam a tecnologia do feitio dos tijolos e outros artefatos cerâmicos, como as manilhas o que possibilita o que hoje chamamos de arquitetura romana e seus sistemas de água e esgoto tão importantes para o crescimento de sua população. Com a expansão dos Império Romano a tecnologia foi se difundindo em vários locais da Europa e interagindo com o conhecimento local derivando então outras variações de artefatos.

Na Ásia, nos séculos VI e VII chineses descobrem a porcelana, que devido a sua alta resistência e delicadeza torna-se a cerâmica mais cobiçada e valiosa já produzida. Seu conhecimento foi disseminado pelas rotas de comércio levando-a à várias partes da Europa. Nesta mesma época o Império Islâmico invade a Europa através da Península Ibérica dominando os povos e levando consigo a tecnologia da fabricação dos azulejos. O período de invasão dos muçulmanos durou até o século XV marcando de forma permanente a cultura portuguesa e espanhola.

Durante este período, em outros locais da Europa, eram desenvolvidas e aprimoradas outras técnicas de fabricação cerâmica. Surgem a maiólica, a faiança, o grês e no século XVII os alemães, depois de muitas tentativas, conseguem reproduzir a porcelana chinesa. No século XVIII fábricas de porcelana são abertas em toda a Europa.

Como podemos observar a cerâmica que hoje conhecemos possui uma longa trajetória histórica até chegar aquilo que hoje encontramos e consumimos com enorme facilidade e diversidade.

\section{CERÂMICA PORTUGUESA}

Após a expulsão dos muçulmanos das terras portuguesas, no ano de 1492 , foi possível verificar as marcas culturais deixadas pelos invasores. A cerâmica é uma delas, principalmente a azulejaria que teve suas técnicas aprimoradas pelo conhecimento dos árabes muçulmanos que por ali estiveram durante a invasão.

No início do século XV Portugal realiza uma série de importações de azulejos de cunho hispano-mourisco, renascentistas e maneirista, vindo dos principais centros de produção como Sevilha. Só a partir de 1560 é que Portugal inicia produção própria seguindo a técnica da maiólica.

No Brasil há registros de importação de azulejos datados do século XVII, são azulejos vindos não só de Portugal, mas também da Holanda e outros países.

Em Portugal várias fábricas nascem neste período e muitas delas têm farta produção que vão dos azulejos às peças cerâmicas ornamentais como vasos, esculturas e objetos utilitários. Segundo autores a produção cerâmica portuguesa possui requinte e qualidade tendo sido classificada como obras comparadas a arte da ourivesaria.

Devido a sua localização a cidade do Porto foi um grande pólo cerâmico em terras 
lusas. O Brasil recebeu muitas peças derivadas de Fábricas como a Real Fábrica de Louças do Rato (1769 - 1835), Fábrica de Cerâmica e Fundição das Devezas (1865 - 1915), Fábrica de Louças Massarelos (1766-1936) e a Fábrica de Santo Antonio do Vale da Piedade (1784 - 1886), entre outras.

Com as guerras napoleônicas a produção portuguesa entrou em declínio vindo a fechar algumas fábricas e após a queda de Napoleão ressurgiram e continuaram suas produções.

Devido as nossas raízes portuguesas, o Brasil possui exemplares desta produção cerâmica a qual foi largamente importada de Portugal no final do século XVII. No entanto, esta se concentra em cidades da região sudeste e nordeste. Porto Alegre apesar de sua colonização açoriana, não apresenta muitos exemplares que nos contam esta história. Perdemos ou nunca as tivemos?

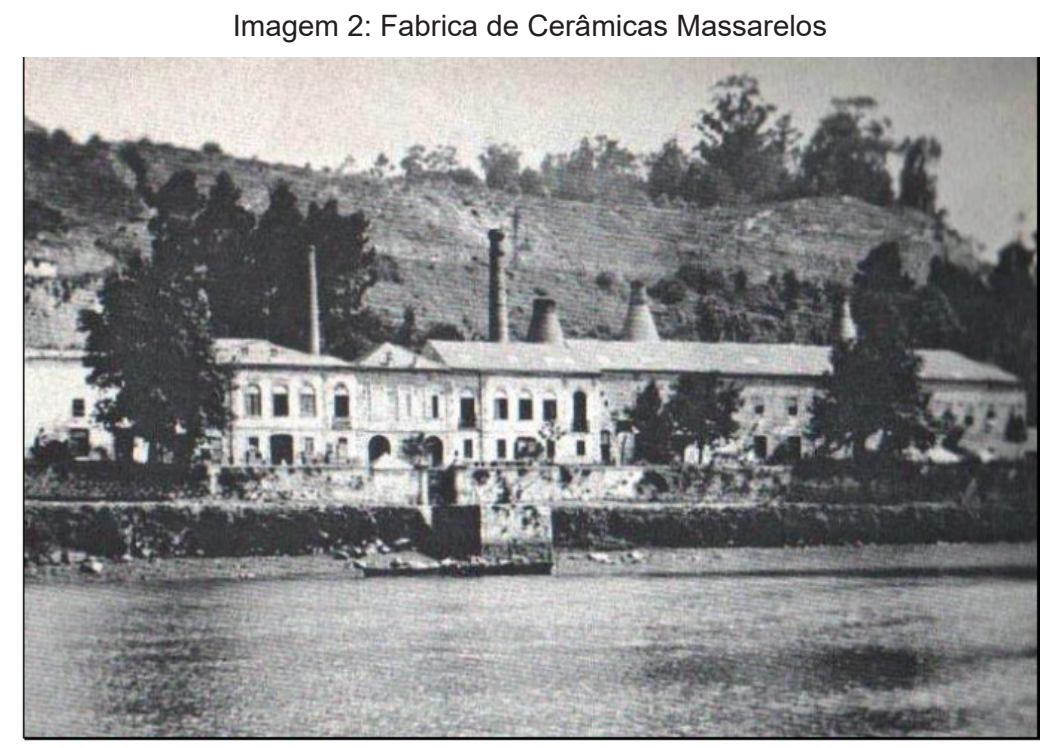

Fonte: http://portodeantanho.blogspot.com²

Imagem 3: Azulejo relevado Manufatura de Massarelos

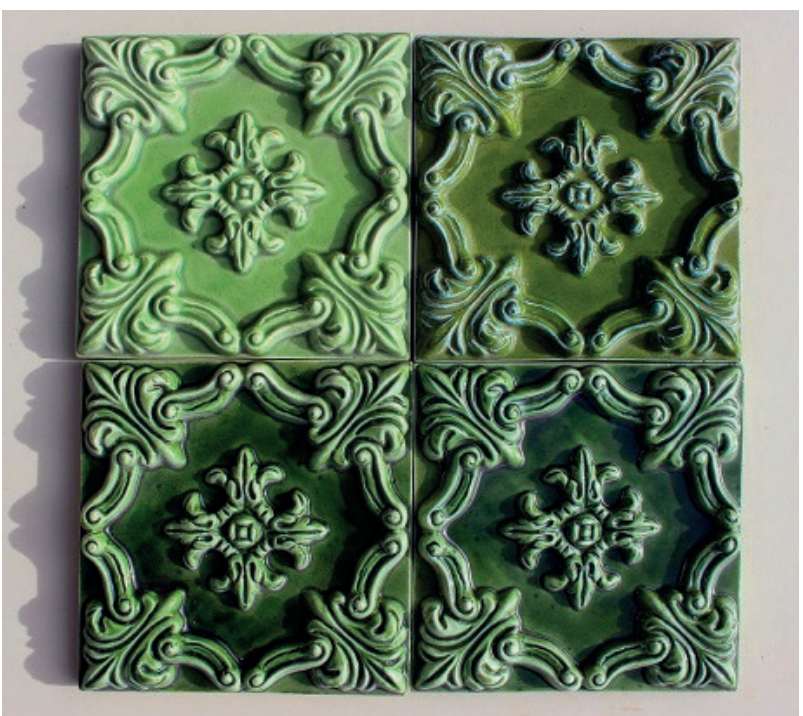

Fonte: Blog tempohistorias.blogspot.com ${ }^{3}$ 


\section{PORTO ALEGRE E A CERÂMICA PORTUGUESA}

Quando andamos pela cidade de Porto Alegre, o que impera na paisagem urbana do seu centro histórico são as edificações ecléticas. A presença da cerâmica é percebida apenas em cinco edificações as quais tem neste material sua identidade através do seu emprego como revestimento de fachada, as mesmas estão localizadas nas ruas Andradas, Duque de Caxias e José Montaury. Todas com fachadas revestidas podem azulejos da Fábrica de Massarelos. Preservadas pela legislação de tombamento municipal, as casas resistem ao tempo como testemunhos de uma longa trajetória tecnológica e histórica.

Os azulejos, apesar de serem tardios, representam técnicas desenvolvidas pela Fábrica de Louças e Faianças de Massarelos fundada em 1766 por Manoel Duarte Silva. Importante pela fabricação de azulejos relevados. Para nós porto-alegrenses um museu de rua onde podemos observar o trabalho desta importante tradição lusa.

Imagem 4: Fachadas azulejadas centro histórico Porto Alegre

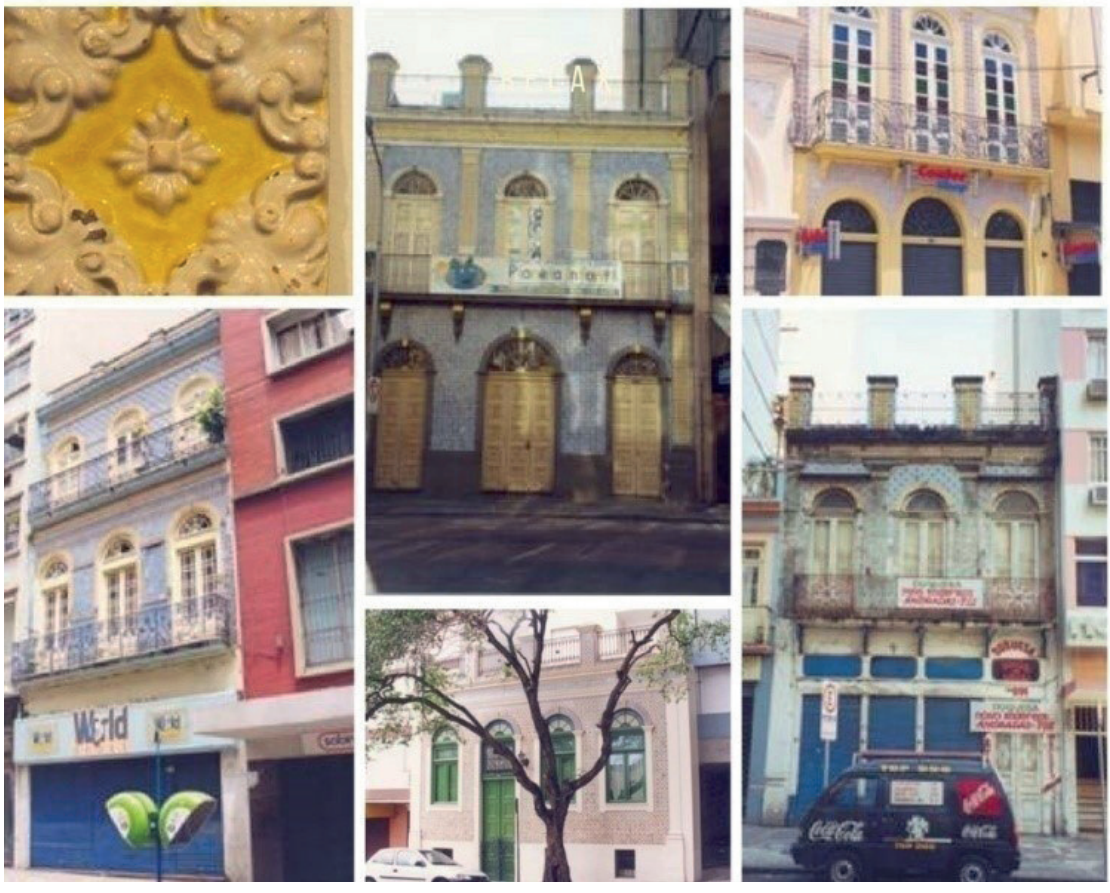

Fonte: Fotos cedidas por Ana Flores

No tocante a elementos decorativos de fachada, a cidade não manteve registros fáceis de serem visualizados. Não podemos afirmar aqui que não existiram em quantidade significativa, ou que simplesmente não foram conservados. No entanto, dois registros ainda figuram seja no imaginário, seja na presença física destes. São as edificações "Casa do Leões" e o Solar dos Câmara.

A Casa dos Leões, datada do início do século XX, recebeu esta denominação justamente pela presença de dois leões cerâmicos que encimavam o portão de entrada da residência. Atualmente, não existem mais e seu paradeiro não foi identificado.

Chegado o aniversário de 200 anos do Solar dos Câmara, nosso olhar se volta para a edificação construída em 1818, e percebemos que este contribui com registros da faiança portuguesa da tradicional Fábrica de Santo Antônio do Porto. Durante uma reforma feita no século passado, recebeu ornatos cerâmicos em suas fachadas. Um conjunto escultórico de 
5 figuras femininas representando os cinco continentes foram instaladas na platibanda do prédio e vasos cerâmicos no jardim interno à edificação.

Enquanto as cerâmicas da Casa dos Leões não foram identificadas, as cerâmicas do Solar dos Câmara, apesar de terem sido recolhidas no seu interior, ainda estão disponíveis para apreciação e pesquisa. Elas manifestam as cerâmicas da Fábrica de Santo Antonio do Porto.

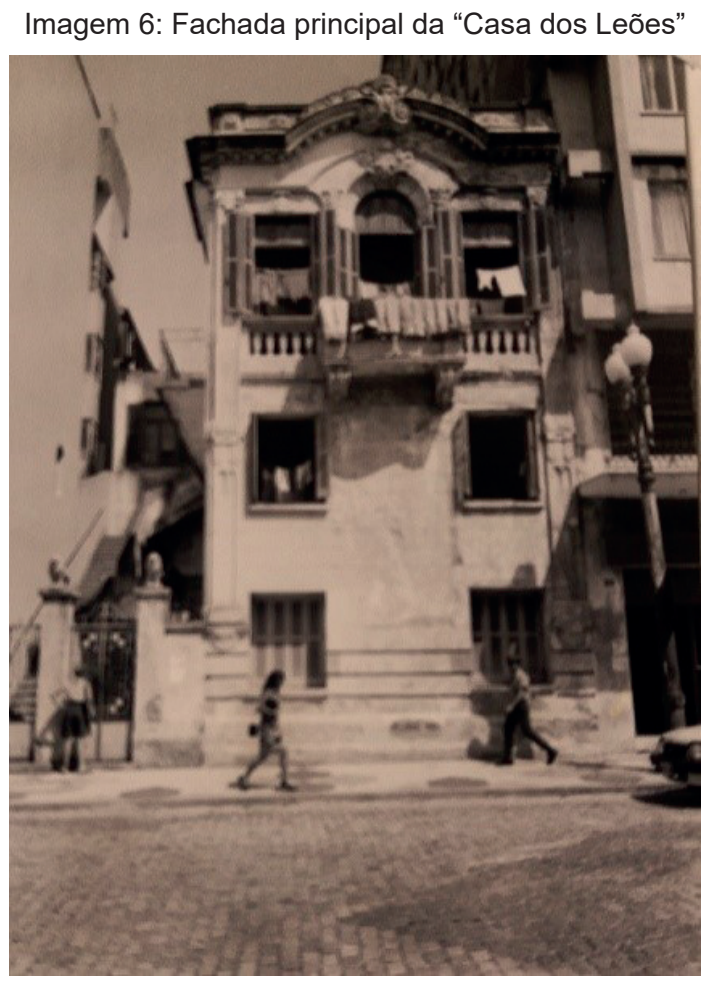

Fonte: Blog do http:www.rogerierina.com.br ${ }^{4}$

Figura 6: Detalhe do portão de entrada com os leões de cerâmica

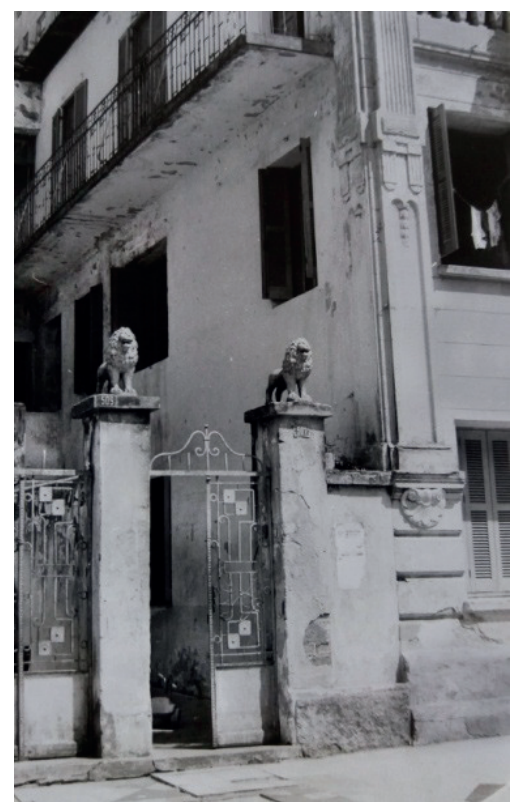

Fonte: Blog http://www.rogerlerina.com.br ${ }^{5}$ 


\section{SOLAR DOS CÂMARA}

Embora não estejam mais localizados nas fachadas do Solar, o mesmo já exibiu como ornatos fachadistas, o conjunto escultórico cerâmico intitulado "Os Cinco Continentes" e vasos, oriundos da antiga Fábrica de Santo Antonio do Vale da Piedade.

As esculturas cerâmicas, todas na cor branca, imitam esculturas de mármore, muito valorizadas artisticamente.

Figura 7: Vista da fachada principal do Solar dos Câmara início do século XX.

Conjunto escultórco sobre platibanda

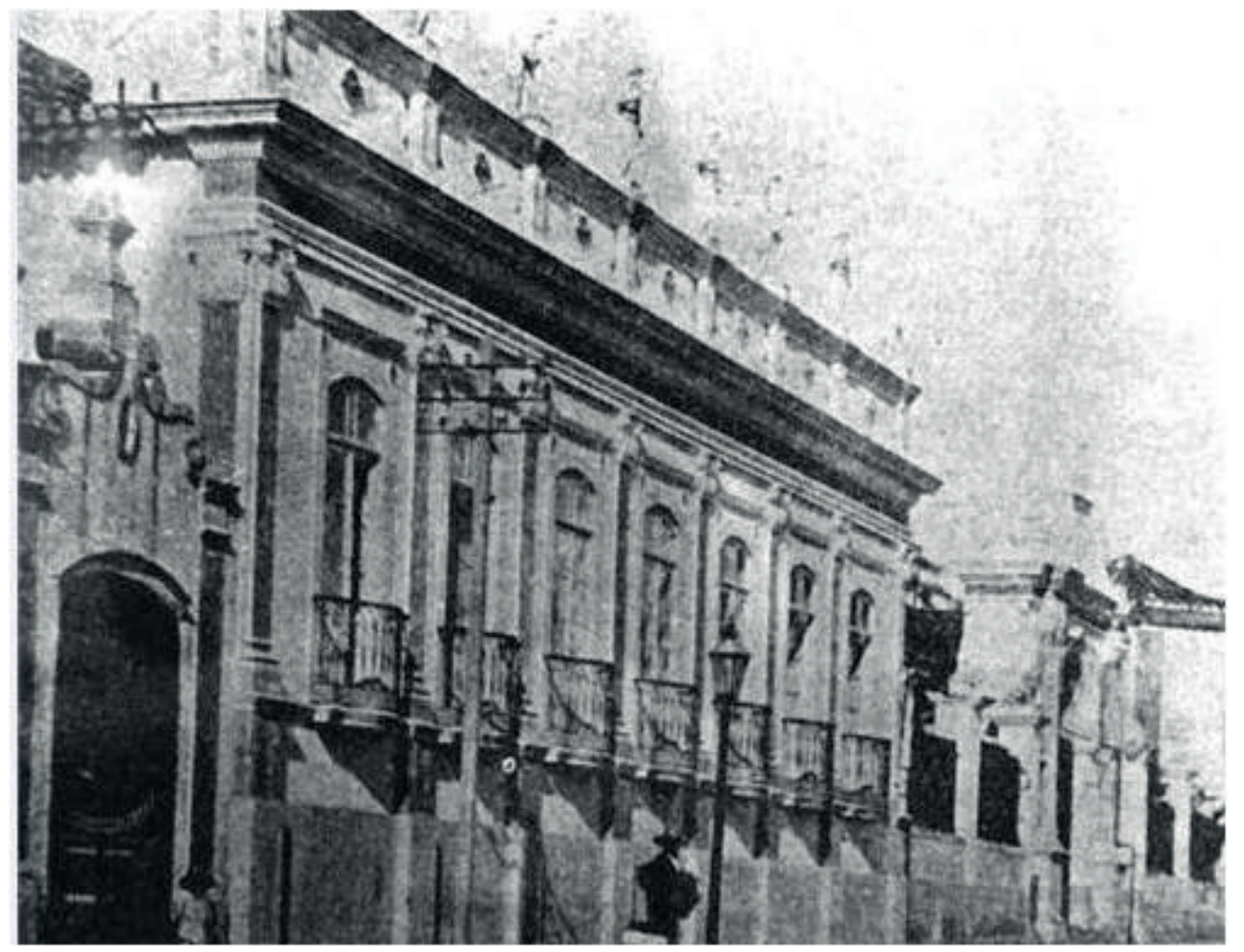

Fonte: Acervo Biblioteca Borges de Medeiros

Infelizmente, as mesmas não estão mais localizadas nas áreas externas da edificação. Uma questão de conservação das peças que ao longo dos anos sofreram com a ação de vários agentes de degradação como os poluentes atmosféricos e a própria ação antrópica. Em 2004 as peças passaram por restauração e como prevenção foram recolhidas para a área interna do Solar, onde podem ser visitadas e apreciadas como um exemplar da cerâmica produzida pela importante Fábrica de Santo Antônio (1784-1886), localizada no Vale da Piedade na cidade do Porto. 
Figura 8 - Conjunto escultórico "Os Cinco Continentes" e vaso em faiança portuguesa

Na ordem: Oceania, Europa, África, Ásia e América
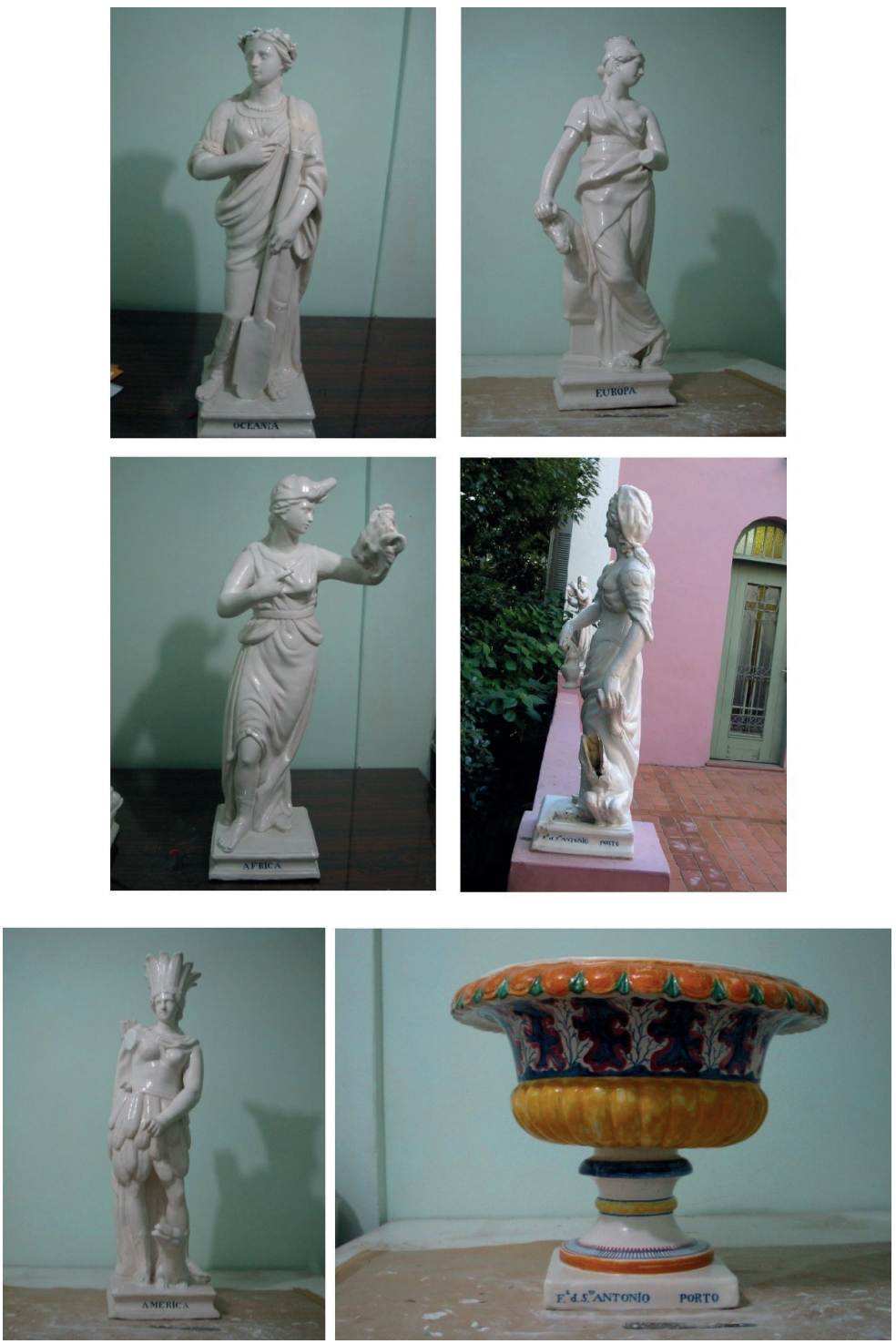

Fonte: Acervo particular autora

\section{CONSIDERAÇÕES FINAIS}

A riqueza que se observa em outras cidades do nosso país, quanto ao acervo da cerâmica lusa é com certeza, de grande beleza. Cidades com grande concentração de renda nos séculos XVIII e XIX tiveram como bem integrado à arquitetura belos exemplares herdados da tradição cerâmica portuguesa.

Porto Alegre possui, de fato, não apenas poucos remanescentes como também peças tardias como a azulejaria fachadista das casas do centro histórico. No entanto, apesar e principalmente pela escassez deste acervo, estes objetos tornaram-se de grande valor. Mantê-los conservados é ainda mais imprescindível, pois uma vez perdidos a cidade não poderá oferecer aos seus habitantes e visitantes este pedaço tão importante da nossa história, uma história rica que nos mostra séculos de interações geopolíticas, transmissão de conhecimento tecnológico e riqueza cultural. 


\section{NOTAS}

1. Disponível em: <https:/li.pinimg.com/originals/04/6d/d2/046dd23a8ca939e08eabbb5f9a354557.jpg>.

2. Disponível em: <http://portodeantanho.blogspot.com/2017/05/continuacao-2.html>.

3. Disponível em: <http://tempohistorias.blogspot.com/2014/04/azulejos-de-massarelos-ou-um-passeio-de.html>.

4. Disponível em: <http://www.rogerlerina.com.br/uploads/ggfd44c4ec64e0c63f968e862dde1881c3.jpg>.

5. Disponível em: <http://www.rogerlerina.com.br/uploads/ggb7c6918d5685c72a25f57735ee7d781a. jpg $>$.

\section{REFERÊNCIAS}

ALVA BALDERRAMA, Alejandro; ALMAGRO VIDAL, Ana; BUSTUÉ CARDIEL, Isabel Bestué. (eds) El studio y la conservación de la cerâmica decorada en arquitectura. ICCROM Conservation Studies, ICCROM, Rome, 2003.

CONCEIÇÃO, Américo; GOMES, Simão. Porto de Antanho: Cerâmicas à beira-rio. 2017. Blogspot. Disponível em: <http://portodeantanho.blogspot.com/2017/05/continuacao-2.html>

FERREIRA, Ivete. Tempo e Historias: Azulejos de Massarelos ou um passeio de Lisboa a Torre de Moncorvo. 2014. Blogspot. Disponível em: <http://tempohistorias.blogspot.com/2014/04/azulejos-demassarelos-ou-um-passeio-de.html>. Acesso em: jul. 2018.

LERINA, Roger. Bolg do Roger Lerina. Disponível em: <http://www.rogerlerina.com.br/uploads/ ggfd44c4ec64e0c63f968e862dde1881c3.jpg>.

Bolg do Roger Lerina. Disponível em: <http://www.rogerlerina.com.br/uploads/ ggb7c6918d5685c72a25f57735ee7d781a.jpg>.

Recebido em: 18/10/2018

Aceito em: 24/10/2018 